\title{
Study on Europium-Doped Hydroxyapatite Nanoparticles by Fourier Transform Infrared Spectroscopy and Their Antimicrobial Properties
}

\author{
Simona-Liliana Iconaru, ${ }^{1,2}$ Mikael Motelica-Heino, ${ }^{2}$ and Daniela Predoi ${ }^{1}$ \\ ${ }^{1}$ Department of Multifunctional Materials and Structures Laboratory, National Institute of Materials Physics, 105 Bis Atomistilor, \\ P.O. Box MG 07, 077125 Magurele, Romania \\ ${ }^{2}$ ISTO, Université d'Orléans, 45067 Orléans Cedex 02, France
}

Correspondence should be addressed to Daniela Predoi; dpredoi@gmail.com

Received 16 May 2013; Accepted 8 August 2013

Academic Editor: Maciej Sitarz

Copyright (C) 2013 Simona-Liliana Iconaru et al. This is an open access article distributed under the Creative Commons Attribution License, which permits unrestricted use, distribution, and reproduction in any medium, provided the original work is properly cited.

Fourier transform infrared spectroscopy (FT-IR) analysis was conducted on europium-doped hydroxyapatite, $\mathrm{Ca}_{10-x} \mathrm{Eu}_{x}$ $\left(\mathrm{PO}_{4}\right)_{6}(\mathrm{OH})_{2}$ nanocrystalline powders (Eu:HAp) with $0 \leq x_{\mathrm{Eu}} \leq 0.2$. Antimicrobial studies were also performed for the first time on Eu:HAp. The antimicrobial properties of Eu:HAp nanoparticles with $0 \leq x_{\mathrm{Eu}} \leq 0.2$ on Gram-negative (E. coli ATCC 25922, Pseudomonas aeruginosa 1397) and Gram-positive (Staphylococcus aureus 0364, Enterococcus faecalis ATCC 29212) bacteria systems and a species of fungus (Candida albicans ATCC 10231) were reported. Our study demonstrates that the antimicrobial activity of Eu:HAp nanoparticles is dependent on the europium concentration.

\section{Introduction}

Hydroxyapatite $\left(\mathrm{Ca}_{10}\left(\mathrm{PO}_{4}\right)_{6}(\mathrm{OH})_{2}\right)$ is the main inorganic component of human bones and teeth, showing a very good biocompatibility, bioactivity, and osteoconductivity due to its nontoxic, and noninflammatory properties [1-9]. Therefore, it has been widely used in many fields, like biomedical applications, as a bioactive coating material for metallic implants, clinical bone augmentation, dental implantology, tumors treatment, and cell activation, or it could be also used as a carrier in drug delivery systems [10]. Moreover, trivalent rare-earth-ion-doped hydroxyapatite can also be used as a biological fluorescent probes due to its excelent luminescent properties.

In the last years, a special emphasis was put on development and characterization of rare-earth based inorganic luminescent nanoparticles with a great interest for biomedical applications [11-14]. The most important applications could be found on pharmaceutical industry or biological and medical diagnostics [15-17].

The hydroxyapatite doped with rare-earth ions can be used as a fluorescent probes, the intensity of luminescence in this case depends on the concentration of rare-earth ions used as dopant as well as the degree of crystallinity and the crystal structure of the host material [18-20]. Over the past decade, several methods for obtaining luminescent inorganic nanoparticles have been developed, including coprecipitation and sol-gel synthesis which allow adjusting the particles morphology, size, structure, and composition in order to adapt their physical and chemical properties [14, 21-23].

Fluorescent labeling is an indispensable technique which is widely used for performing nondestructive observations both in vivo and in vitro by replacing the calcium ions in hydroxyapatite crystal lattice using rare-earth luminescent ions [24-26]. The hexagonal hydroxyapatite allows the substitutions of many rare-earth ions without any changes in the crystal structure [27-30]. Nowadays, the hydroxyapatite nanoparticles doped with rare earths ions are being studied very intently as cell labeling materials, as a result of their strong luminescence under visible light spectrum [31-36].

Compared to other rare-earth elements, trivalent Europium $\mathrm{Eu}^{3+}$ ions have a simple electronic energy level scheme and hypersensitive transitions. The $\mathrm{Eu}^{3+}$-doped calcium 
apatites represent a good biological probe candidate due to their low toxicity and stable luminescence over time, and it has been proven that a small amount of europium in the bioactivity behaviour has no harmful effects [37-41]. The ionic radius similarity between $\mathrm{Ca}^{2+}$ and $\mathrm{Eu}^{3+}$ in the apatite lattice makes them a good host for $\mathrm{Eu}^{3+}$ doping [4].

Recently, great attention has been paid to europiumdoped hydroxyapatite (Eu:HAp) potential use as a biological probe [30]. Previously, the europium-doped hydroxyapatite was studied applying PL $[32,33]$. On the other hand, IR spectroscopy is a powerful method in ionic investigation and has been used extensively in phosphate minerals research [42-44].

Concerning the phase composition of the as-prepared Eu:HAp various studies have been reported [31-33, 45]. In our recent studies no other additional phases were observed [45] for the synthesized Eu:HAp samples, and the diffraction patterns were identical to that obtained for stoichiometric apatite. In this paper, the obtained Eu:HAp samples were systematically characterized by Fourier transform infrared (FTIR) spectroscopy. The aim of this work is to contribute to the study of the influence of europium in the structure of hydroxyapatite. On the other hand, cell viability from various doses of the Eu:HAp samples at two different time points was compared with corresponding culture media values. After $24 \mathrm{~h}$ and $48 \mathrm{~h}$ exposures to all types of Eu:HAp at $10 \mu \mathrm{g} / \mathrm{mL}$ concentration, the morphology of the cells was preserved. Moreover, we report in this work for the first time the bacterial studies on Eu:HAp. Furthermore, in this paper, original studies on antimicrobial activities of Eu:HAp against Gram-positive (Staphylococcus aureus 0364, Enterococcus faecalis ATCC 29212), Gram-negative (E. coli ATCC 25922, Pseudomonas aeruginosa 1397), and fungal strains (Candida albicans ATCC 10231) are presented.

\section{Materials and Methods}

2.1. Samples. All the reagents for synthesis, including ammonium dihydrogen phosphate $\left[\left(\mathrm{NH}_{4}\right)_{2} \mathrm{HPO}_{4}\right]$, calcium nitrate $\left[\mathrm{Ca}\left(\mathrm{NO}_{3}\right)_{2} \cdot 4 \mathrm{H}_{2} \mathrm{O}\right]$, and europium nitrate $\left[\mathrm{Eu}\left(\mathrm{NO}_{3}\right)_{3} \cdot 6 \mathrm{H}_{2} \mathrm{O}\right]$ (Alpha Aesar), were used as purchased, without purification. Europium-doped hydroxyapatite (Eu:HAp, $\mathrm{Ca}_{10-x} \mathrm{Eu}_{x}$ $\left.\left(\mathrm{PO}_{4}\right)_{6}(\mathrm{OH})_{2}\right)$ nanoparticles were performed by setting $x_{\mathrm{Eu}}=$ $0.01, x_{\mathrm{Eu}}=0.02, x_{\mathrm{Eu}}=0.05, x_{\mathrm{Eu}}=0.1, x_{\mathrm{Eu}}=0.2$ and $[\mathrm{Ca}+$ $\mathrm{Eu}] / \mathrm{P}$ as 1.67 in accord with [45].

2.2. Fourier Transform Infrared (FTIR) Spectroscopy. The functional groups present in the prepared nanoparticles and thin films were identified by FTIR using a Perkin Elmer, Spectrum BX spectrometer. In order to obtain the nanoparticles spectra, $1 \%$ of the nanopowder was mixed and ground with $99 \% \mathrm{KBr}$. Tablets of $10 \mathrm{~mm}$ diameter were prepared by pressing the powder mixture with a pressure of not more than $10 \mathrm{psi}$. The spectrum was recorded in the range of 400 to $4000 \mathrm{~cm}^{-1}$ with $4 \mathrm{~cm}^{-1}$ resolution. The first FTIR spectra were obtained after 256 scans at room temperature $\left(25 \pm 0.5^{\circ} \mathrm{C}\right)$. The second derivative IR spectra were acquired after 5-point smoothing of the original IR spectra. For selected spectral ranges, the peak fitting analyses were performed using procedures of Kolmas et al. [46]: (i) baseline correction, (ii) second derivative calculation and self-deconvolution assessment in order to determine the number and positions of the bands, and (iii) curve fittings with fixed peak positions using Lorentzienne lines. In the previous studies Matsuhiro and Rivas [47] and GómezOrdóñez and Rupérez [48] showed that second derivatives of FTIR spectra are generally used as an aid for wavenumber determination of weak absorption bands to improve resolution of overlapped bands in the original spectra. To that end, in our studies derivation including Savitzky-Golay algorithm with nine smoothing points was performed.

2.3. Antimicrobial Studies. The microbial strains identification was confirmed by the aid of VITEK II automatic system. VITEK cards for identification and susceptibility testing were inoculated and incubated according to the manufacturer's recommendations. Microbial suspensions of $1.5 \times 10^{8} \mathrm{CFU} / \mathrm{mL}$ corresponding to $0.5 \mathrm{McF}$ arland density obtained from $15-18 \mathrm{~h}$ bacterial cultures developed on solid media were used in our experiments. The tested substances were solubilised in DMSO, and the starting stock solution was of $5000 \mu \mathrm{g} / \mathrm{mL}$ concentration. The qualitative screening was performed by an adapted disk diffusion method [49-53].

\section{Results and Discussions}

3.1. IR Absorbance Spectra. The FTIR spectra of Eu:HAp were recorded in the typical absorption mode from $\mathrm{KBr}$ pellets. IR absorbance spectra of Eu:HAp samples with various europium concentrations $\left(0 \leq x_{\mathrm{Eu}} \leq 0.2\right)$ are shown in the $4000 \mathrm{~cm}^{-1}$ to $400 \mathrm{~cm}^{-1}$ range in Figure 1 . In our previous studies [45], we have shown that, for all the samples, the presence of strong $[\mathrm{OH}]^{-}$vibration peak $\left(632 \mathrm{~cm}^{-1}\right)$ could be noticed. The broad bands in the regions 1600$1700 \mathrm{~cm}^{-1}$ and $3200-3600 \mathrm{~cm}^{-1}$ correspond to $\mathrm{H}-\mathrm{O}-\mathrm{H}$ bands of lattice water. Fowler in his infrared studies on apatites [54] showed that the band at $3570 \mathrm{~cm}^{-1}$ is characterized by $[\mathrm{OH}]^{-}$ stretching mode and the band at $632 \mathrm{~cm}^{-1}$ is characterized by $[\mathrm{OH}]^{-}$arising from stretching librational mode. The bands at around $1090 \mathrm{~cm}^{-1}$ and about $1040 \mathrm{~cm}^{-1}$ can be attributed to the $v_{3}\left[\mathrm{PO}_{4}\right]^{3-}$ while the band at 962 arises from $v_{1}$ $\left[\mathrm{PO}_{4}\right]^{3-}$. The $602 \mathrm{~cm}^{-1}$ and $564 \mathrm{~cm}^{-1}$ bands appear from $v_{4}$ $\left[\mathrm{PO}_{4}\right]^{3-}$. Markovik et al. [55] presented that the sharpness of bands, especially sharpness of the $632 \mathrm{~cm}^{-1}, 602 \mathrm{~cm}^{-1}$, and $564 \mathrm{~cm}^{-1}$ bands, indicates a well-crystallized HAp. The band at $475 \mathrm{~cm}^{-1}$ can be attributed to the $v_{2}\left[\mathrm{PO}_{4}\right]^{3-}[56]$. In the FTIR spectrum of Eu:HAp with $x_{\mathrm{Eu}} \geq 0.1$ (Figure 1), the bands corresponding to the $v_{3}$ vibration of $\mathrm{C}-\mathrm{O}$ were observed at $1410 \mathrm{~cm}^{-1}$, characteristic of the carbonate group $[57,58]$.

The intensity of the band located at $1410 \mathrm{~cm}^{-1}$ in the spectrum of Eu:HAp samples with $x_{\mathrm{Eu}} \geq 0.1$ is attributed to components of the $v_{3}$ mode of a trace amount of $\left[\mathrm{CO}_{3}\right]^{2-}$. The $\nu_{2}$ vibrations between 850 and $890 \mathrm{~cm}^{-1}$, characteristic of the carbonate group, were not detected because $v_{2}\left[\mathrm{CO}_{3}\right]^{2-}$ band at $872 \mathrm{~cm}^{-1}$ is hidden by $\left[\mathrm{HPO}_{4}\right]^{2-}$ band at $875 \mathrm{~cm}^{-1}$. Similar comportment was observed by Markovik et al. [55] in their studies on preparation and comprehensive characterization 

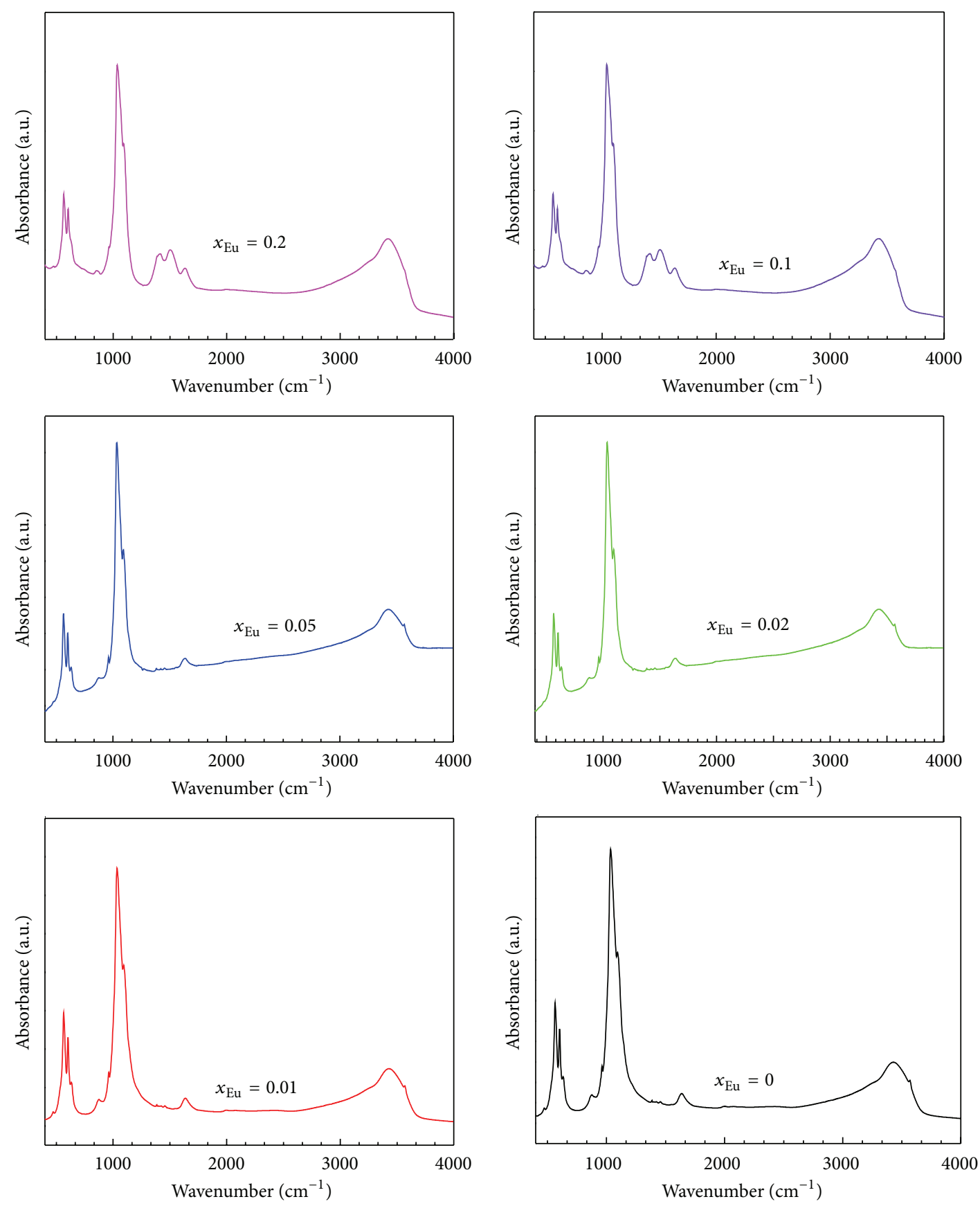

FIGURE 1: FT-IR spectra of europium-doped hydroxyapatite (Eu:HAp) with $x_{\mathrm{Eu}}=0, x_{\mathrm{Eu}}=0.02$, and $x_{\mathrm{Eu}}=0.2$.

of calcium hydroxyapatite. Holcomb and Young [59] showed that the $\left[\mathrm{CO}_{3}\right]^{2-}$ band at $1410 \mathrm{~cm}^{-1}$ derives from $\left[\mathrm{CO}_{3}\right]^{2-}$ (designated by "B-type" carbonate that replaces $\mathrm{PO}_{4}{ }^{3-}$ ions in the hydroxyapatite lattice). The band at $1510 \mathrm{~cm}^{-1}$ was also detected in the FT-IR spectrum of Eu:HAp with $x_{\mathrm{Eu}} \geq 0.1$. The band at $1510 \mathrm{~cm}^{-1}$ derives from $\left[\mathrm{CO}_{3}\right]^{2-}$ (designated by "A-type" carbonate) that replaces $\mathrm{OH}^{-}$ions in the hydroxyapatite lattice $[55,60]$. In all the spectra of Eu:HAp samples, the band at $875 \mathrm{~cm}^{-1}$ was detected. This band is supposed to arise due to $\left[\mathrm{HPO}_{4}\right]^{2-}$ ions from several reasons [55].

In Figure 1, we observed that the contribution of the area that corresponds to the phosphate bands decreases when the europium concentration in the samples increases. The bands at 475 and $962 \mathrm{~cm}^{-1}$ progressively disappear with the increase of europium concentration. When $x_{\mathrm{Eu}}=0.2$, the bands at 475 and $962 \mathrm{~cm}^{-1}$ are almost absent. We can also observe in the Eu:HAp spectra a broadening of peak vibration with the decrease of the europium concentration. This behaviour was observed by Owada et al. [61] in sintered Y-doped hydroxyapatite.

3.2. IR Second Derivative Spectra. In order to complete structural information on the analyzed Eu:HAp samples with $0 \leq x_{\mathrm{Eu}} \leq 0.2$, we agreed to perform derivative analysis and 

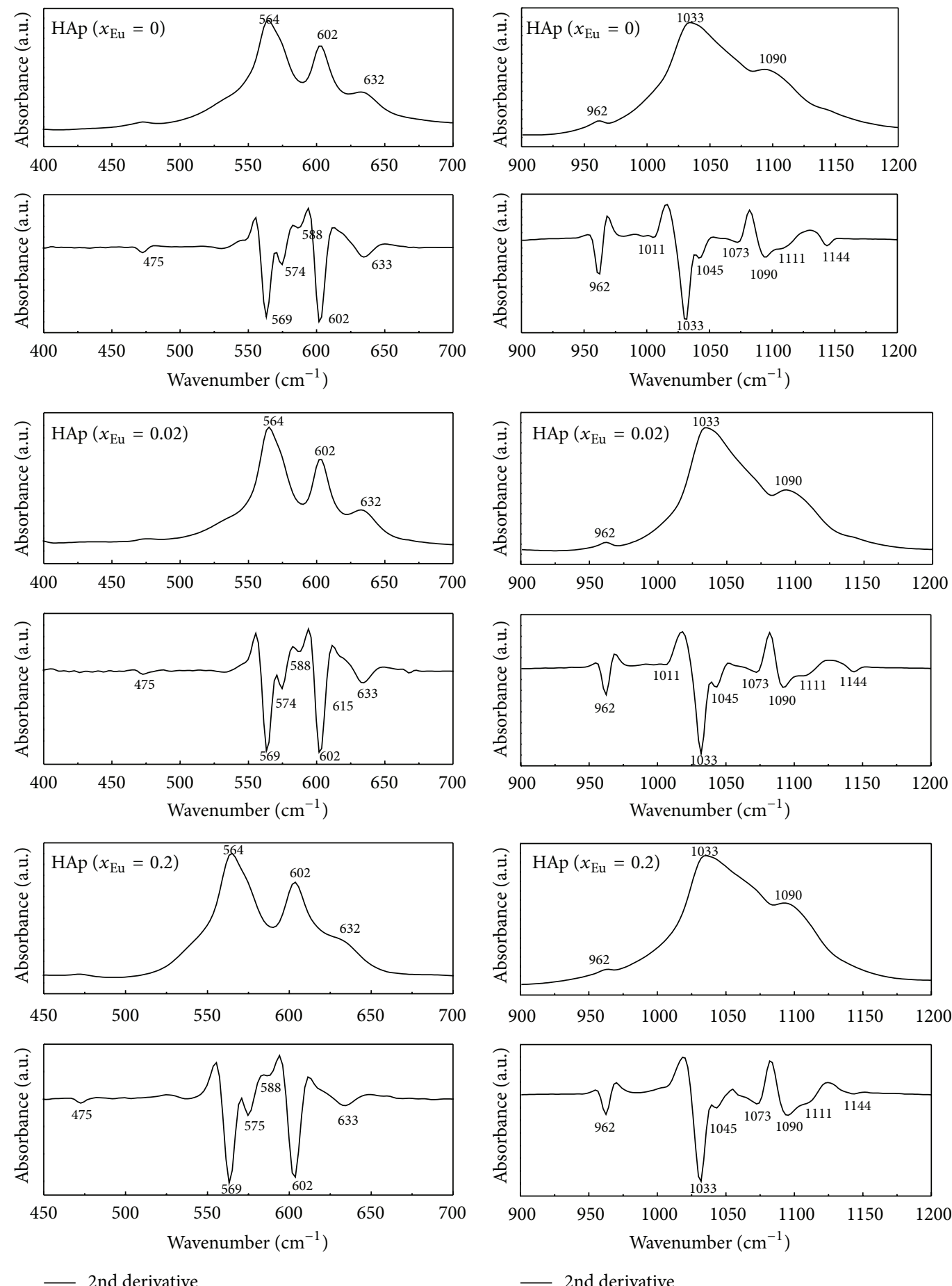

FIGURE 2: Second derivative of Eu:HAp $\left(x_{\mathrm{Eu}}=0, x_{\mathrm{Eu}}=0.02\right.$, and $\left.x_{\mathrm{Eu}}=0.2\right)$ spectrum of the $v_{4}, v_{3}, v_{2}$, and $\nu_{1}$ domains.

peak fitting of selected $v_{4}, v_{3}, v_{2}$, and $v_{1}$ phosphate bands. The second derivative of the spectrum of Eu:HAp samples $\left(x_{\mathrm{Eu}}=0, x_{\mathrm{Eu}}=0.02, x_{\mathrm{Eu}}=0.2\right)$ in the $v_{4}, v_{3}$, and $\nu_{1}\left[\mathrm{PO}_{4}\right]^{3-}$ bands is shown in Figure 2. Only the results obtained for pure $\operatorname{HAp}\left(x_{\mathrm{Eu}}=0\right)$ and Eu:HAp $\left(x_{\mathrm{Eu}}=0.02, x_{\mathrm{Eu}}=0.2\right)$ samples are shown, which are clearly assigned to the strong changes that occur in the FT-IR spectra of HAp in the presence of Eu. $v_{1}\left[\mathrm{PO}_{4}\right]^{3-}$ band was observed at around $962 \mathrm{~cm}^{-1}$ in the second derivative spectra. On the other hand, in the second derivative spectra was identified a $v_{2}\left[\mathrm{PO}_{4}\right]^{3-}$ band at $475 \mathrm{~cm}^{-1}$. In concordance with precedent studies, the bands assigned in the second derivative spectra of Eu:HAp ( $0 \leq$ $\left.x_{\mathrm{Eu}} \leq 0.2\right)$ can be attributed to molecular vibrations of the phosphate $\left[\mathrm{PO}_{4}\right]^{3-}$ in an apatitic stoichiometric environment of hydroxyapatite [62].

To evaluate the subtle spectral changes occurring as a consequence of the europium-doped hydroxyapatite, the spectra in the spectral regions of $450-700 \mathrm{~cm}^{-1}\left(\nu_{2}\right.$ and $v_{4}\left[\mathrm{PO}_{4}\right]^{3-}$ 

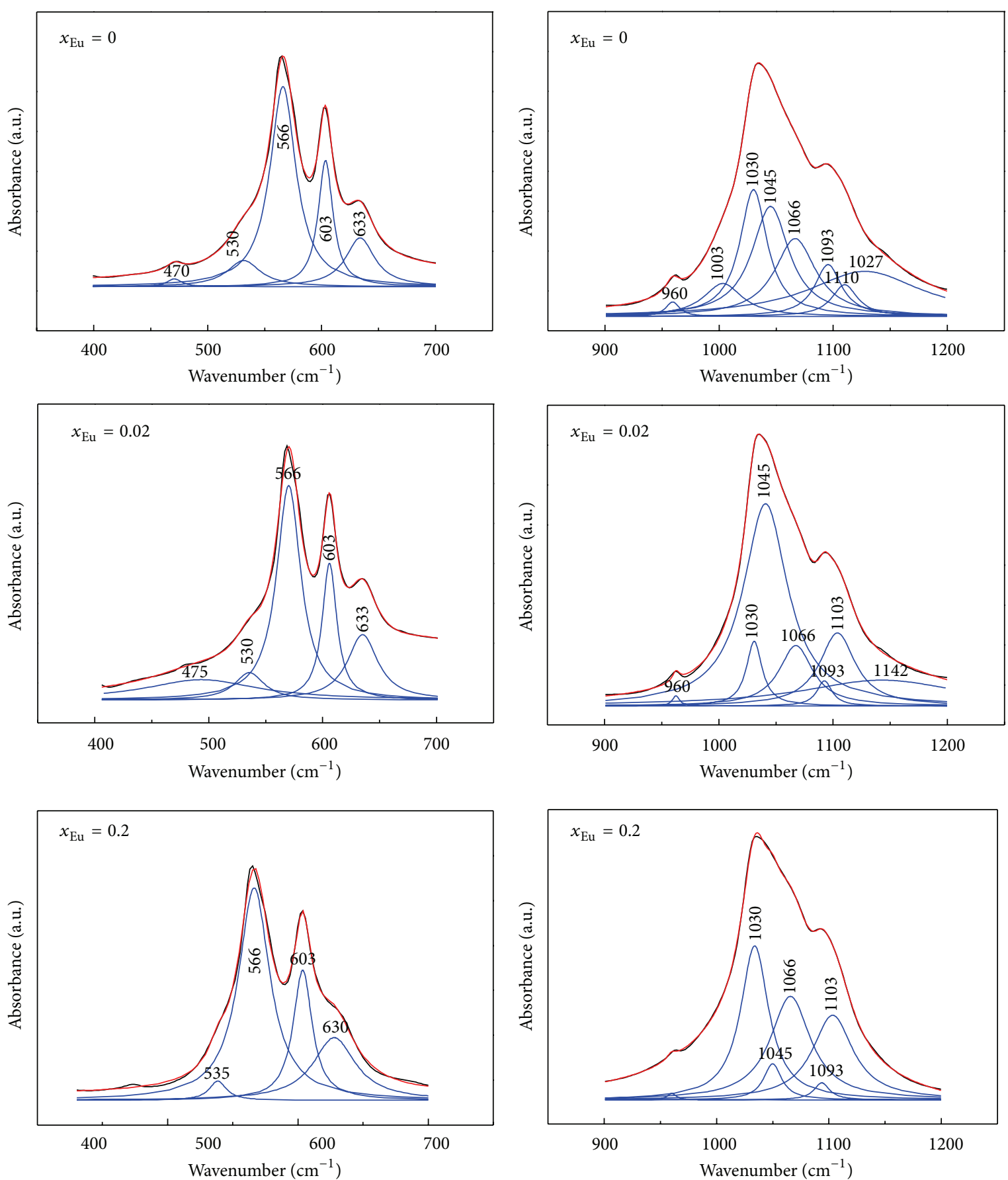

FIGURE 3: FT-IR deconvoluted spectra of the $v_{4}, v_{3}, v_{2}$, and $v_{1}$ domain for Eu:HAp $\left(x_{\mathrm{Eu}}=0, x_{\mathrm{Eu}}=0.02\right.$, and $\left.x_{\mathrm{Eu}}=0.2\right)$.

domain) and $900-1200 \mathrm{~cm}^{-1}\left(\nu_{1}\right.$ and $\nu_{3}\left[\mathrm{PO}_{4}\right]^{3-}$ domains) were analyzed by means of second derivative (Figure 2) and curve fitting analysis (Figure 3).

In Figure 2, we also observe the second derivative band at $633 \mathrm{~cm}^{-1}$ that derives from the $\mathrm{OH}^{-}$librational mode. IR wavenumber position $\left(\mathrm{cm}^{-1}\right)$ of the $v_{4}, v_{3}, v_{2}$, and $v_{1}$ $\left[\mathrm{PO}_{4}\right]^{3-}$ bands of Eu:HAp spectrum from second derivative is presented in Table 1. Ten bands were detected for phosphate bands of hexagonal Eu:HAp samples.

Figure 3 shows the FT-IR spectrum of hydroxyapatite $\left(x_{\mathrm{Eu}}=0\right)$, the phosphate $v_{4}, v_{3}, v_{2}$, and $v_{1}$ regions with experimental and calculated contours overlaid along with the individual subbands (blue) as determined by a curve fitting analysis. Five components were needed for a satisfactory fit in the spectral region of $450-700 \mathrm{~cm}^{-1}\left(v_{2}\right.$ and $v_{4}\left[\mathrm{PO}_{4}\right]^{3-}$ domain) and eight in the spectral region of $900-1200 \mathrm{~cm}^{-1}$ $\left(\nu_{1}\right.$ and $\nu_{3}\left[\mathrm{PO}_{4}\right]^{3-}$ domains). FT-IR spectrum of Eu:HAp with $x_{\mathrm{Eu}}=0.02$ is also presented, and five components were needed for a satisfactory fit in the spectral region of 450$700 \mathrm{~cm}^{-1}\left(v_{2}\right.$ and $v_{4}\left[\mathrm{PO}_{4}\right]^{3-}$ domain) and six in the spectral region of $900-1200 \mathrm{~cm}^{-1}\left(\nu_{1}\right.$ and $\nu_{3}\left[\mathrm{PO}_{4}\right]^{3-}$ domains). For Eu:HAp samples with $x_{\mathrm{Eu}}=0.2$, four components were 
TABLE 1: IR wavenumber position $\left(\mathrm{cm}^{-1}\right)$ of $v_{4}, v_{3}, v_{2}$, and $v_{1}\left[\mathrm{PO}_{4}\right]^{3-}$ bands of Eu:HAp spectrum from second derivative.

\begin{tabular}{lcc}
\hline Assignments & Position $\left(\mathrm{cm}^{-1}\right)$ & References \\
\hline$v_{1}\left[\mathrm{PO}_{4}\right]^{3-}$ & 962 & {$[62]$} \\
$v_{2}\left[\mathrm{PO}_{4}\right]^{3-}$ & 475 & {$[62]$} \\
$v_{3}\left[\mathrm{PO}_{4}\right]^{3-}$ & $1033 ; 1045 ; 1073 ; 1090$ & {$[62]$} \\
$v_{4}\left[\mathrm{PO}_{4}\right]^{3-}$ & $569 ; 575 ; 588 ; 602$ & {$[62]$} \\
$\begin{array}{l}\text { Present in newly } \\
\text { precipitated apatite }\end{array}$ & 1111 & {$[62,74]$} \\
{$\left[\mathrm{HPO}_{4}\right]^{2-}$} & & \\
containing & 1144 & {$[74]$} \\
apatites & & \\
{$\left[\begin{array}{l}\text { OH }]^{-} \text {group } \\
\text { (librational mode })\end{array}\right.$} & 633 & {$[74,75]$} \\
\hline
\end{tabular}

needed for a satisfactory fit in the spectral region of 450$700 \mathrm{~cm}^{-1}\left(v_{2}\right.$ and $v_{4}\left[\mathrm{PO}_{4}\right]^{3-}$ domain) and five important components in the spectral region of $900-1200 \mathrm{~cm}^{-1}\left(\nu_{1}\right.$ and $v_{3}\left[\mathrm{PO}_{4}\right]^{3-}$ domains).

The individual component for phosphate $v_{2}$ region (featured near $475 \mathrm{~cm}^{-1}$ ) decreases for the samples with $x_{\mathrm{Eu}}=$ 0.02 and disappears when $x_{\mathrm{Eu}}$ increases to 0.2 . The high frequency shoulder is more clearly defined for pure Hap than in the case of the Eu:HAp with $x_{\mathrm{Eu}}=0.02$ and $x_{\mathrm{Eu}}=0.2$ in the $v_{1}$ and $v_{3}$ phosphate regions. The band requires at least eight components for an adequate fit to the spectrum, compared with only six in the case of Eu:HAp with $x_{\mathrm{Eu}}=0.02$ or only five in the Eu:HAp with $x_{\mathrm{Eu}}=0.2$. In this series of materials, it was not realistic to attempt to identify particular components characteristic the particle size. However, a correlation was found between the percentage area of the $\nu_{1}$ band (near $960 \mathrm{~cm}^{-1}$ ) and the crystal size. The individual component for the phosphate $\nu_{1}$ region (band near $960 \mathrm{~cm}^{-1}$ ) disappears when $x_{\mathrm{Eu}}$ increases to 0.2 . On the other hand, the individual component for phosphate $v_{3}$ region (band near $1040 \mathrm{~cm}^{-1}$ ) decreases for the samples with $x_{\mathrm{Eu}}=0.02$. However, in Figures 2 and 3, we observe the disappearance of the band at $1144 \mathrm{~cm}^{-1}$, which is associated with $\left[\mathrm{HPO}_{4}\right]^{2-}$ ions [63].We note that the main molecular species that gave rise to the Eu:HAp $\left(x_{\mathrm{Eu}}=0, x_{\mathrm{Eu}}=0.02, x_{\mathrm{Eu}}=0.2\right)$ absorbance in the $900-1200 \mathrm{~cm}^{-1}$ region was assigned to the phosphate ion, $\left[\mathrm{PO}_{4}\right]^{3-}$.

3.3. Antimicrobial Studies. A study on enhancement of osteoblast proliferation on europium-doped hydroxyapatite has rarely been reported. Anselme [64] in his study concerning osteoblast adhesion on biomaterials and García and Reyes [65] in the study of bioadhesive surfaces to promote osteoblast differentiation and bone formation showed that often synthetic materials do not support osteoblast adhesion and this may result in poor cell differentiation and limited bone formation. Keselowsky et al. [66] in the study on surface chemistry and McFarland et al. [67]. in their study on protein adsorption and cell attachment to patterned surfaces demonstrated that the effect of surface properties on cellular

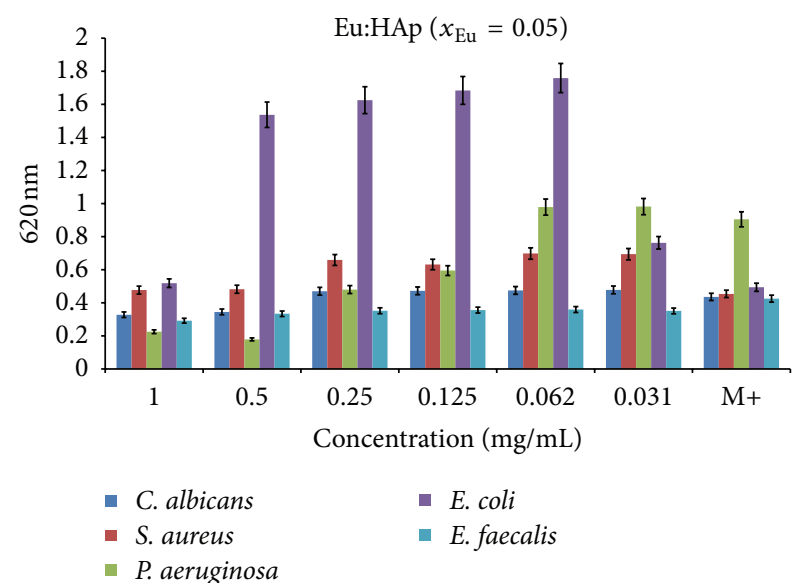

Figure 4: Antimicrobial activity of as-prepared Eu:HAp samples $\left(x_{\mathrm{Eu}}=0.05\right)$ on E. coli ATCC 25922, Pseudomonas aeruginosa 1397, Staphylococcus aureus 0364, Enterococcus faecalis ATCC 29212, and Candida albicans ATCC 10231.

response depends on differences in species, concentration, and biological activity of adsorbed proteins, which may be obtained from different sources, that is, biological fluids and cell-mediated synthesis and deposition.

The antimicrobial activity of Eu:HAp $\left(0 \leq x_{\mathrm{Eu}} \leq 0.2\right)$ nanoparticles was tested using the most common bacterial pathogens and fungus: E. coli ATCC 25922 (Gram-negative), Pseudomonas aeruginosa 1397 (Gram-negative), Staphylococcus aureus 0364 (Gram-positive), Enterococcus faecalis ATCC 29212 (Gram-positive), and Candida albicans ATCC 10231 (fungus).

The antimicrobial studies on Eu:HAp $\left(0 \leq x_{\mathrm{Eu}} \leq 0.02\right)$ nanoparticles indicated that antimicrobial activity is present. The results of antimicrobial activity of Eu:HAp $\left(0.05 \leq x_{\mathrm{Eu}} \leq\right.$ 0.2 ) nanoparticles are shown in Figures 4-6. For the asprepared Eu:HAp samples, an antibacterial activity was not observed on E. coli ATCC 25922 (Figures 4-6). The Eu:HAp nanoparticles with $x_{\mathrm{Eu}}=0.05$ showed a good antibacterial activity on Enterococcus faecalis ATCC 29212 (Figure 6) for all the concentrations studied (from $0.031 \mathrm{mg} / \mathrm{mL}$ to $1 \mathrm{mg} / \mathrm{mL}$ ). For the samples of Eu:HAp with $x_{\mathrm{Eu}}=0.1$ and $x_{\mathrm{Eu}}=$ 0.2 (Figures 5 and 6), we have observed that the inhibition of Enterococcus faecalis ATCC 29212 was more evident. In the samples with $x_{\mathrm{Eu}}=0.1$, the inhibition was observed for concentrations higher than $0.062 \mathrm{mg} / \mathrm{mL}$. For the asprepared Eu:HAp samples with $x_{\mathrm{Eu}}=0.2$, the inhibition was observed for all concentrations. For Candida albicans ATCC 10231, a good inhibition was observed for samples with $x_{\mathrm{Eu}}=0.2$ (Figure 6).

For samples with $x_{\mathrm{Eu}}=0.05$ and $x_{\mathrm{Eu}}=0.1$, the inhibition was observed at high concentrations (Figures 46). Additionally, a very good inhibition of Pseudomonas aeruginosa 1397 has been noticed when the concentration of Eu:HAp $\left(0.05 \leq x_{\mathrm{Eu}} \leq 0.2\right)$ increased from $0.125 \mathrm{mg} / \mathrm{mL}$ to $1 \mathrm{mg} / \mathrm{mL}$. Raimondi et al. [68] and Morones et al. [69], studying the inhibition of bacterial growth by differentially shaped nanoparticles, showed that the antimicrobial efficacy of the nanoparticles depends on the shape of the nanoparticles. 


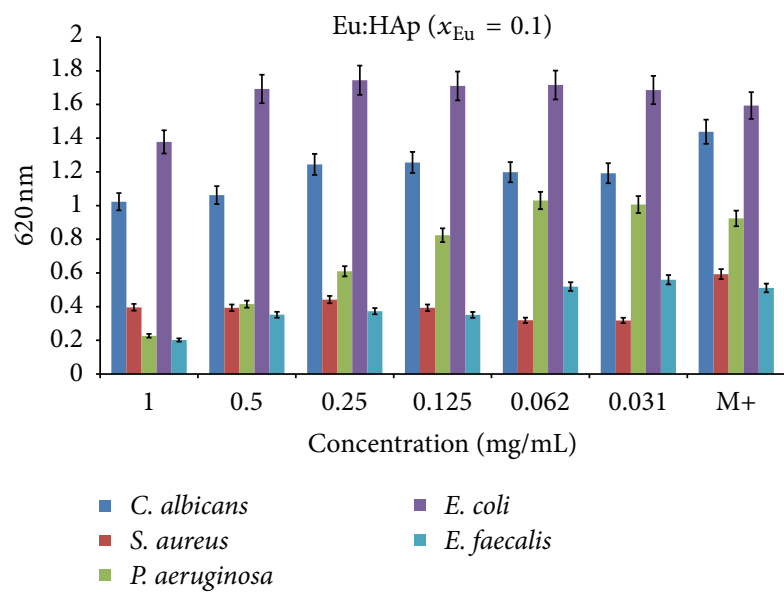

FIgURE 5: Antimicrobial activity of as-prepared Eu:HAp samples $\left(x_{\mathrm{Eu}}=0.1\right)$ on E. coli ATCC 25922, Pseudomonas aeruginosa 1397, Staphylococcus aureus 0364, Enterococcus faecalis ATCC 29212, and Candida albicans ATCC 10231.

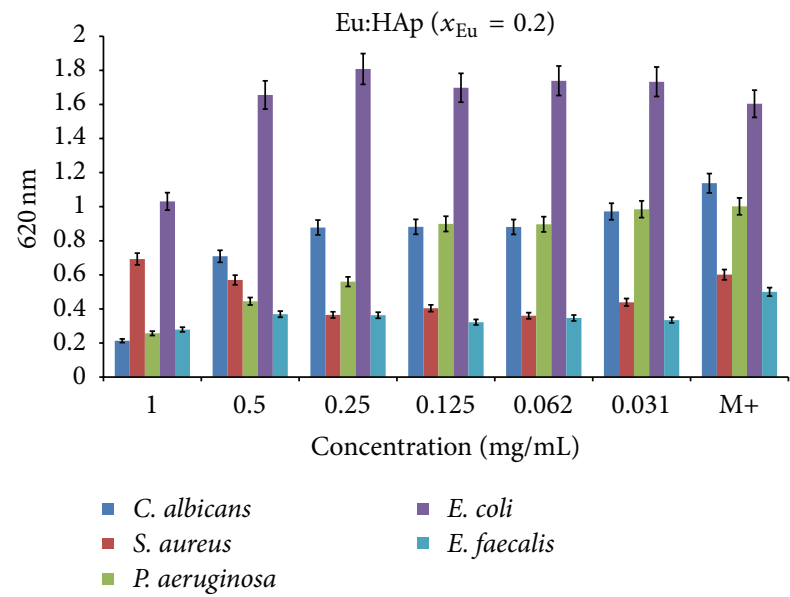

Figure 6: Antimicrobial activity of as-prepared Eu:HAp samples $\left(x_{\mathrm{Eu}}=0.2\right)$ on E. coli ATCC 25922, Pseudomonas aeruginosa 1397, Staphylococcus aureus 0364, Enterococcus faecalis ATCC 29212, and Candida albicans ATCC 10231.

One of the aims of this study was to obtain an Eu:HAp stoichiometric apatite and to contribute to the study of the influence of europium in the structure of hydroxyapatite. We note that it is possible to determine the type of apatite, nonstoichiometric or stoichiometric, using Fourier deconvolution techniques. This study allowed highlighting the stoichiometry of Eu:HAp biomaterials, based on changes in the phosphate $v_{1}$ and $v_{3}$ absorbances in the $900-1200 \mathrm{~cm}^{-1}$ spectral region. Sauer and Wuthier [70] in their studies claimed that the presence of the $\left[\mathrm{PO}_{4}\right]^{3-}$ doublet at 602 and $567 \mathrm{~cm}^{-1}$ in all the composites suggests that the precursor phase of the HAp was octacalcium phosphate, OCP, $\left(\mathrm{Ca}_{8} \mathrm{H}_{2}\left[\mathrm{PO}_{4}\right]_{6}\right)$. On the other hand, they showed that the OCP precursor ensures a more crystalline and ordered HAp phase. Granja et al. [71] in their previous studies have affirmed that if the precursor had been amorphous calcium phosphate (ACP) $\left(\mathrm{Ca}_{2}\left[\mathrm{PO}_{4}\right]_{3}\right)$, these $\left[\mathrm{PO}_{4}\right]^{3-}$ bands should be a broad singlet instead of a doublet. Moreover, Hutchens et al. in 2006 [72] evidenced that ACP precipitation requires the rapid interaction between $\mathrm{Ca}^{2+}$ and $\left[\mathrm{PO}_{4}\right]^{3-}$ at high supersaturation instead of precursor complexation with other species. A previous study of apatite minerals realized by Rey et al. in 1991 [73], using Fourier deconvolution analysis, has attributed a $1020 \mathrm{~cm}^{-1}$ band to nonstoichiometric apatite containing $\left[\mathrm{HPO}_{4}\right]^{2-}$ and $\left[\mathrm{CO}_{3}\right]^{2-}$ and the band at $1125 \mathrm{~cm}^{-1}$ in FT-IR deconvoluted spectra to stoichiometric apatite. Due to the presence of the band at around $1127 \mathrm{~cm}^{-1}$ in all the prepared samples, our present studies have shown that the Eu:HAp is a stoichiometric apatite.

Moreover, our present study demonstrates that the antibacterial activity of Eu:HAp nanoparticles is dependent on the europium concentration. Furthermore, the inhibitory effect was found to be dependent on the increase of concentration from $0.031 \mathrm{mg} / \mathrm{mL}$ to $1 \mathrm{mg} / \mathrm{mL}$.

\section{Conclusions}

In the present work, we contributed to the study of the influence of europium in structure of hydroxyapatite. Using Fourier deconvolution techniques, we showed that it is possible to determine the type of Eu:HAp apatite, nonstoichiometric or stoichiometric. The spectra of Eu:HAp samples in the spectral regions of $450-700 \mathrm{~cm}^{-1}$ and $900-1200 \mathrm{~cm}^{-1}$ were analyzed by means of second derivative and using Fourier deconvolution analysis. This study allowed highlighting the stoichiometry of Eu:HAp biomaterials, based on changes in the phosphate $\nu_{1}$ and $\nu_{3}$ absorbances in the $900-1200 \mathrm{~cm}^{-1}$ spectral region.

The antimicrobial activity of Eu:HAp $\left(0 \leq x_{\mathrm{Eu}} \leq 0.2\right)$ nanoparticles was tested using the most common bacterial pathogens and fungus: E. coli ATCC 25922 (Gram-negative), Pseudomonas aeruginosa (Gram-negative), Staphylococcus aureus 0364 (Gram-positive), Enterococcus faecalis ATCC 29212 (Gram-positive), and Candida albicans ATCC 10231 (fungus).

In summary, this study on the antimicrobial activity of Eu:HAp $\left(0 \leq x_{\mathrm{Eu}} \leq 0.2\right)$ nanoparticles describes a nanotechnology-based strategy where luminescent $\mathrm{Eu}^{3+}$-doped hydroxyapatite represents a potential application for drug release and targeting based on their luminescent properties. These results and methods could be interesting for academic and industrial researchers in biomaterials, potential orthopedic medical materials, and drug carriers.

\section{Conflict of Interests}

The authors declare that they have no conflict of interests.

\section{Acknowledgments}

The financial and encouragement support provided by the ministry of Education of Romania under the Project IFACEA no. C2-06 is acknowledged. The authors gratefully acknowledge the support given to this work by Dr. F. Massuyeau from the Institut des Matériaux-Jean Rouxel, Nantes. 


\section{References}

[1] R. Z. LeGeros and J. P. LeGeros, "Calcium phosphate bioceramics: past, present and future," Key Engineering Materials, vol. 240-242, pp. 3-10, 2003.

[2] L. L. Hench and J. Wilson, "Surface-active biomaterials," Science, vol. 226, no. 4675, pp. 630-636, 1984.

[3] W. Suchanek and M. Yoshimura, "Processing and properties of hydroxyapatite-based biomaterials for use as hard tissue replacement implants," Journal of Materials Research, vol. 13, no. 1, pp. 94-117, 1998.

[4] C. Srinivasa Rao, K. Upendra Kumar, and C. K. Jayasankar, "Luminescence properties of $\mathrm{Eu}^{3+}$ ions in phosphate-based bioactive glasses," Solid State Sciences, vol. 13, no. 6, pp. 13091314, 2011.

[5] L. L. Hench, R. J. Splinter, W. C. Allen, and T. K. Greenlee, "Bonding mechanisms at the interface of ceramic prosthetic materials," Journal of Biomedical Materials Research, vol. 5, no. 6, pp. 117-141, 1972.

[6] I. Izquierdo-Barba and M. Vallet-Regí, "Fascinating properties of bioactive templated glasses: a new generation of nanostructured bioceramics," Solid State Sciences, vol. 13, no. 4, pp. 773783, 2011.

[7] M. Vallet-Regí, F. Balas, and D. Arcos, "Mesoporous materials for drug delivery," Angewandte Chemie (International Edition), vol. 46, no. 40, pp. 7548-7558, 2007.

[8] L. L. Hench and J. M. Polak, "Third-generation biomedical materials," Science, vol. 295, no. 5557, pp. 1014-1017, 2002.

[9] D. Arcos, R. P. del Real, and M. Vallet-Regí, "Biphasic materials for bone grafting and hyperthermia treatment of cancer," Journal of Biomedical Materials Research A, vol. 65, no. 1, pp. 71-78, 2003.

[10] L. L. Hench, "Bioceramics: from concept to clinic," Journal of the American Ceramic Society, vol. 74, pp. 1487-1510, 1991.

[11] J. H. Rao, A. Dragulescu-Andrasi, and H. Q. Yao, "Fluorescence imaging in vivo: recent advances," Current Opinion in Biotechnology, vol. 18, pp. 17-25, 2007.

[12] J. Zhou, Y. Sun, X. X. Du, L. Q. Xiong, H. Hu, and F. Y. Li, "Dual-modality in vivo imaging using rare-earth nanocrystals with near-infrared to near-infrared (NIR-to-NIR) upconversion luminescence and magnetic resonance properties," Biomaterials, vol. 31, no. 12, pp. 3287-3295, 2010.

[13] F. Chen, P. Huang, Y.-J. Zhu, J. Wu, and D.-X. Cui, "Multifunctional $\mathrm{Eu}^{3+} / \mathrm{Gd}^{3+}$ dual-doped calcium phosphate vesiclelike nanospheres for sustained drug release and imaging," Biomaterials, vol. 33, pp. 6447-6455, 2012.

[14] S. Dembski, S. Rupp, M. Milde et al., "Synthesis and optical properties of luminescent core-shell structured silicate and phosphate nanoparticles," Optical Materials, vol. 33, no. 7, pp. 1106-1110, 2011.

[15] H. Chander, "Development of nanophosphors-a review," Materials Science and Engineering R, vol. 49, no. 5, pp. 113-155, 2005.

[16] H. A. Höppe, "Recent developments in the field of inorganic phosphors," Angewandte Chemie (International Edition), vol. 48, no. 20, pp. 3572-3582, 2009.

[17] J. Shen, L.-D. Sun, and C.-H. Yan, "Luminescent rare earth nanomaterials for bioprobe applications," Dalton Transactions, no. 42 , pp. 5687-5697, 2008.

[18] T. S. de Araujo, Z. S. MacEdo, P. A. S. C. De Oliveira, and M. E. G. Valerio, "Production and characterization of pure and $\mathrm{Cr}^{3+}$ doped hydroxyapatite for biomedical applications as fluorescent probes," Journal of Materials Science, vol. 42, no. 7, pp. 22362243, 2007.

[19] R. Jagannathan and M. Kottaisamy, " $\mathrm{Eu}^{3+}$ luminescence: a spectral probe in $\mathrm{M}_{5}\left(\mathrm{PO}_{4}\right)_{3} \mathrm{X}$ apatites $\left(\mathrm{M}=\mathrm{Ca}\right.$ or $\mathrm{Sr} ; \mathrm{X}=\mathrm{F}^{-}, \mathrm{Cl}^{-}$, $\mathrm{Br}^{-}$or $\left.\mathrm{OH}^{-}\right)$," Journal of Physics: Condensed Matter, vol. 7, no. 44, pp. 8453-8466, 1995.

[20] O. A. Graeve, R. Kanakala, A. Madadi, B. C. Williams, and K. C. Glass, "Luminescence variations in hydroxyapatites doped with $\mathrm{Eu}^{2+}$ and $\mathrm{Eu}^{3+}$ ions," Biomaterials, vol. 31, no. 15, pp. 4259-4267, 2010.

[21] R. Dittmeyer, R. W. Keim, G. Reysa, and A. Oberholz, Chemische Technik: Prozesse Und Produkte. Band 2: Neue Technologie, Wiley-VCH, Weinheim, Germany, 2004.

[22] B. M. Tissue, "Synthesis and luminescence of lanthanide Ions in nanoscale insulating hosts," Chemistry of Materials, vol. 10, no. 10, pp. 2837-2845, 1998.

[23] A. Groza, "Review of the processes identified during the polymerization of organic and organosilicon liquid films in atmospheric pressure air corona discharges," Romanian Reports in Physics, vol. 64, pp. 1227-1242, 2012.

[24] F. Wang, W. B. Tan, Y. Zhang, X. Fan, and M. Wang, "Luminescent nanomaterials for biological labelling," Nanotechnology, vol. 17, no. 1, pp. R1-R13, 2006.

[25] F. Meiser, C. Cortez, and F. Caruso, "Biofunctionalization of fluorescent rare-earth-doped lanthanum phosphate colloidal nanoparticles," Angewandte Chemie (International Edition), vol. 43, no. 44, pp. 5954-5957, 2004.

[26] Y. Han, X. Wang, H. Dai, and S. Li, "Synthesis and luminescence of $\mathrm{Eu}^{3+}$ doped hydroxyapatite nanocrystallines: effects of calcinations and $\mathrm{Eu}^{3+}$ content," Journal of Luminescence, vol. 135, pp. 281-287, 2012.

[27] J. Rakovan and R. J. Reeder, "Intracrystalline rare earth element distributions in apatite: surface structural influences on incorporation during growth," Geochimica et Cosmochimica Acta, vol. 60, no. 22, pp. 4435-4445, 1996.

[28] R. Reisfeld, M. Gaft, G. Boulon, C. Panczer, and C. K. Jørgensen, "Laser-induced luminescence of rare-earth elements in natural fluor-apatites," Journal of Luminescence, vol. 69, no. 5-6, pp. 343353, 1996.

[29] I. Mayer, J. D. Layani, A. Givan, M. Gaft, and P. Blanc, "La ions in precipitated hydroxyapatites," Journal of Inorganic Biochemistry, vol. 73, no. 4, pp. 221-226, 1999.

[30] P. Martin, G. Carlot, A. Chevarier, C. Den-Auwer, and G. Panczer, "Mechanisms involved in thermal diffusion of rare earth elements in apatite," Journal of Nuclear Materials, vol. 275, no. 3, pp. 268-276, 1999.

[31] A. Doat, M. Fanjul, F. Pellé, E. Hollande, and A. Lebugle, "Europium-doped bioapatite: a new photostable biological probe, internalizable by human cells," Biomaterials, vol. 24, no. 19, pp. 3365-3371, 2003.

[32] A. Doat, F. Pellé, N. Gardant, and A. Lebugle, "Synthesis of luminescent bioapatite nanoparticles for utilization as a biological probe," Journal of Solid State Chemistry, vol. 177, no. 4-5, pp. 1179-1187, 2004.

[33] A. Doat, F. Pellé, and A. Lebugle, "Europium-doped calcium pyrophosphates: allotropic forms and photoluminescent properties," Journal of Solid State Chemistry, vol. 178, no. 7, pp. 23542362, 2005.

[34] S. P. Mondéjar, A. Kovtun, and M. Epple, "Lanthanide-doped calcium phosphate nanoparticles with high internal crystallinity and with a shell of DNA as fluorescent probes in cell 
experiments," Journal of Materials Chemistry, vol. 17, no. 39, pp. 4153-4159, 2007.

[35] C. S. Ciobanu, S. L. Iconaru, P. le Coustumer, L. V. Constantin, and D. Predoi, "Antibacterial activity of silver-doped hydroxyapatite nanoparticles against gram-positive and gram-negative bacteria," Nanoscale Research Letters, vol. 7, p. 324, 2012.

[36] C. S. Ciobanu, F. Massuyeau, E. Andronescu, M. S. Stan, A. Dinischiotu, and D. Predoi, "Biocompatibility study of europium doped crystalline hydroxyapatite bioceramics," Digest Journal of Nanomaterials and Biostructures, vol. 6, no. 4, pp. 1639-1647, 2011.

[37] J. A. Capobianco, P. P. Proulx, and N. Raspa, "Laser-excited fluorescence spectroscopy and crystal field analysis of europium(III)-doped cordierite glass," Chemical Physics Letters, vol. 160, no. 5-6, pp. 591-596, 1989.

[38] V. Lavín, P. Babu, C. K. Jayasankar, I. R. Martín, and V. D. Rodríguez, "On the local structure of $\mathrm{Eu}^{3+}$ ions in oxyfluoride glasses. Comparison with fluoride and oxide glasses," Journal of Chemical Physics, vol. 115, no. 23, pp. 10935-10944, 2001.

[39] M. Zambelli, M. Abril, V. Lavín, A. Speghini, and M. Bettinelli, "Fluorescence line narrowing spectroscopy of $\mathrm{Eu}^{3+}$ in a niobium tellurite glass," Journal of Non-Crystalline Solids, vol. 345-346, pp. 386-390, 2004.

[40] T. Kushida, "Site-selective fluorescence spectroscopy of $\mathrm{Eu}^{3+}$ and $\mathrm{Sm}^{2+}$ ions in glass," Journal of Luminescence, vol. 100, no. 1-4, pp. 73-88, 2002.

[41] H. Doweidar, "Density-structure correlations in $\mathrm{Na}_{2} \mathrm{O}-\mathrm{CaO}-$ $\mathrm{P}_{2} \mathrm{O}_{5}-\mathrm{SiO}_{2}$ bioactive glasses," Journal of Non-Crystalline Solids, vol. 355, no. 9, pp. 577-580, 2009.

[42] R. L. Frost, S. J. Mills, and M. L. Weier, "Peisleyite an unusual mixed anion mineral-a vibrational spectroscopic study," Spectrochimica Acta A, vol. 61, no. 1-2, pp. 177-184, 2005.

[43] M. E. Fleet and X. Liu, "Coupled substitution of type A and B carbonate in sodium-bearing apatite," Biomaterials, vol. 28, no. 6, pp. 916-926, 2007.

[44] M. Sivakumar, T. S. Sampath Kumar, K. L. Shantha, and K. Panduranga Rao, "Development of hydroxyapatite derived from Indian coral," Biomaterials, vol. 17, no. 17, pp. 1709-1714, 1996.

[45] C. S. Ciobanu, S. L. Iconaru, F. Massuyeau, L. V. Constantin, A. Costescu, and D. Predoi, "Synthesis, structure, and luminescent properties of europium-doped hydroxyapatite nanocrystalline powders," Journal of Nanomaterials, vol. 2012, Article ID 942801, 9 pages, 2012.

[46] J. Kolmas, A. Jaklewicz, A. Zima et al., "Incorporation of carbonate and magnesium ions into synthetic hydroxyapatite: the effect on physicochemical properties," Journal of Molecular Structure, vol. 987, no. 1-3, pp. 40-50, 2011.

[47] B. Matsuhiro and P. Rivas, "Second-derivative Fourier transform infrared spectra of seaweed galactans," Journal of Applied Phycology, vol. 5, no. 1, pp. 45-51, 1993.

[48] E. Gómez-Ordóñez and P. Rupérez, "FTIR-ATR spectroscopy as a tool for polysaccharide identification in edible brown and red seaweeds," Food Hydrocolloids, vol. 25, no. 6, pp. 1514-1520, 2011.

[49] J. Uggeri, S. Guizzardi, R. Scandroglio, and R. Gatti, "Adhesion of human osteoblasts to titanium: a morpho-functional analysis with confocal microscopy," Micron, vol. 41, no. 3, pp. 210-219, 2010.

[50] T. M. Buttke, J. A. McCubrey, and T. C. Owen, "Use of an aqueous soluble tetrazolium/formazan assay to measure viability and proliferation of lymphokine-dependent cell lines," Journal of Immunological Methods, vol. 157, no. 1-2, pp. 233-240, 1993.
[51] C. Limban and M. C. Chifiriuc, "Antibacterial activity of new dibenzoxepinone oximes with fluorine and trifluoromethyl group substituents," International Journal of Molecular Sciences, vol. 12, no. 10, pp. 6432-6444, 2011.

[52] C. Limban, L. Marutescu, and M. C. Chifiriuc, "Synthesis, spectroscopic properties and antipathogenic activity of new thiourea derivatives," Molecules, vol. 16, no. 9, pp. 7593-7607, 2011.

[53] L. Marutescu, C. Limban, M. C. Chifiriuc, A.-V. Missir, I. C. Chirita, and M. T. Caproiu, "Studies on the antimicrobial activity of new compounds containing thiourea function," Biointerface Research in Applied Chemistry, vol. 1, no. 6, pp. 236241, 2011.

[54] B. O. Fowler, "Infrared studies of apatites. I. Vibrational assignments for calcium, strontium, and barium hydroxyapatites utilizing isotopic substitution," Inorganic Chemistry, vol. 13, no. 1, pp. 194-207, 1974.

[55] M. Markovic, B. O. Fowler, and M. S. Tung, "Preparation and comprehensive characterization of a calcium hydroxyapatite reference material," Journal of Research of the National Institute of Standards and Technology, vol. 109, no. 6, pp. 553-568, 2004.

[56] W. Jastrzbski, M. Sitarz, M. Rokita, and K. Bułat, "Infrared spectroscopy of different phosphates structures," Spectrochimica Acta A, vol. 79, no. 4, pp. 722-727, 2011.

[57] K. Nakamoto, Infrared and Raman Spectra of Inorganic and Coordination Compounds, John Wiley \& Sons, New York, NY, USA, 1978.

[58] R. Z. LeGeros, G. Bonel, and R. Legros, “Types of " $\mathrm{H}_{2} \mathrm{O}$ ” in human enamel and in precipitated apatites," Calcified Tissue Research, vol. 26, no. 1, pp. 111-118, 1978.

[59] D. W. Holcomb and R. A. Young, "Thermal decomposition of human tooth enamel," Calcified Tissue International, vol. 31, no. 3, pp. 189-201, 1980.

[60] J. C. Elliott, The crystallographic structure of dental enamel and related apatites [Ph.D. thesis], University of London, 1974.

[61] H. Owada, K. Yamashita, T. Umegaki, T. Kanazawa, and M. Nagai, "Humidity-sensitivity of yttrium substituted apatite ceramics," Solid State Ionics, vol. 35, no. 3-4, pp. 401-404, 1989.

[62] C. C. Ribeiro, I. Gibson, and M. A. Barbosa, "The uptake of titanium ions by hydroxyapatite particles-structural changes and possible mechanisms," Biomaterials, vol. 27, no. 9, pp. 17491761, 2006.

[63] C. Paluszkiewicz, A. Ślósarczyk, D. Pijocha et al., "Synthesis, structural properties and thermal stability of Mn-doped hydroxyapatite," Journal of Molecular Structure, vol. 976, no. 1-3, pp. 301-309, 2010.

[64] K. Anselme, "Osteoblast adhesion on biomaterials," Biomaterials, vol. 21, no. 7, pp. 667-681, 2000.

[65] A. J. García and C. D. Reyes, "Bio-adhesive surfaces to promote osteoblast differentiation and bone formation," Journal of Dental Research, vol. 84, no. 5, pp. 407-413, 2005.

[66] B. G. Keselowsky, D. M. Collard, and A. J. García, "Surface chemistry modulates focal adhesion composition and signaling through changes in integrin binding," Biomaterials, vol. 25, no. 28, pp. 5947-5954, 2004.

[67] C. D. McFarland, C. H. Thomas, C. de Filippis, J. C. Steele, and K. E. Healy, "Protein adsorption and cell attachment to patterned surfaces," Journal of Biomedical Materials Research, vol. 49, pp. 200-210, 2000.

[68] F. Raimondi, G. G. Scherer, R. Kötz, and A. Wokaun, "Nanoparticles in energy technology: examples from electrochemistry 
and catalysis," Angewandte Chemie (International Edition), vol. 44, no. 15, pp. 2190-2209, 2005.

[69] J. R. Morones, J. L. Elechiguerra, A. Camacho et al., "The bactericidal effect of silver nanoparticles," Nanotechnology, vol. 16, no. 10, pp. 2346-2353, 2005.

[70] G. R. Sauer and R. E. Wuthier, "Fourier transform infrared characterization of mineral phases formed during induction of mineralization by collagenase-released matrix vesicles in vitro," Journal of Biological Chemistry, vol. 263, no. 27, pp. 13718-13724, 1988.

[71] P. L. Granja, M. A. Barbosa, L. Pouységu, B. De Jéso, F. Rouais, and C. Baquey, "Cellulose phosphates as biomaterials. Mineralization of chemically modified regenerated cellulose hydrogels," Journal of Materials Science, vol. 36, no. 9, pp. 21632172, 2001.

[72] S. A. Hutchens, R. S. Benson, B. R. Evans, H. M. O’Neill, and C. J. Rawn, "Biomimetic synthesis of calcium-deficient hydroxyapatite in a natural hydrogel," Biomaterials, vol. 27, no. 26, pp. 4661-4670, 2006.

[73] C. Rey, M. Shimizu, B. Collins, and M. J. Glimcher, "Resolutionenhanced Fourier transform infrared spectroscopy study of the environment of phosphate ions in the early deposits of a solid phase of calcium-phosphate in bone and enamel, and their evolution with age. I: investigations in the $v 4$ PO4 domain," Calcified Tissue International, vol. 46, no. 6, pp. 384-394, 1990.

[74] C. Rey, M. Shimizu, B. Collins, and M. J. Glimcher, "Resolutionenhanced Fourier Transform Infrared spectroscopy study of the environment of phosphate ion in the early deposits of a solid phase of calcium phosphate in bone and enamel and their evolution with age: 2 . Investigations in the 23 PO4 domain," Calcified Tissue International, vol. 49, no. 6, pp. 383-388, 1991.

[75] M. I. Kay, R. A. Young, and A. S. Posner, "Crystal structure of hydroxyapatite," Nature, vol. 204, no. 4963, pp. 1050-1052, 1964. 

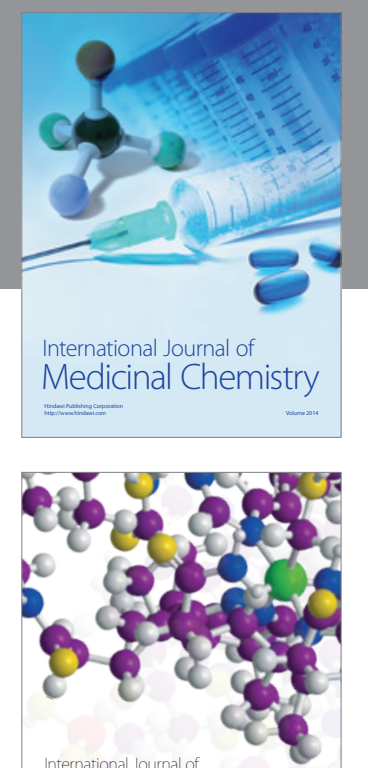

\section{Carbohydrate} Chemistry

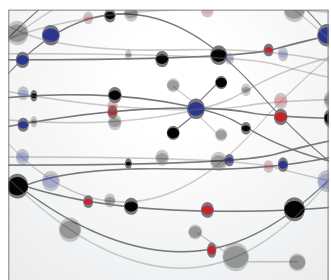

The Scientific World Journal
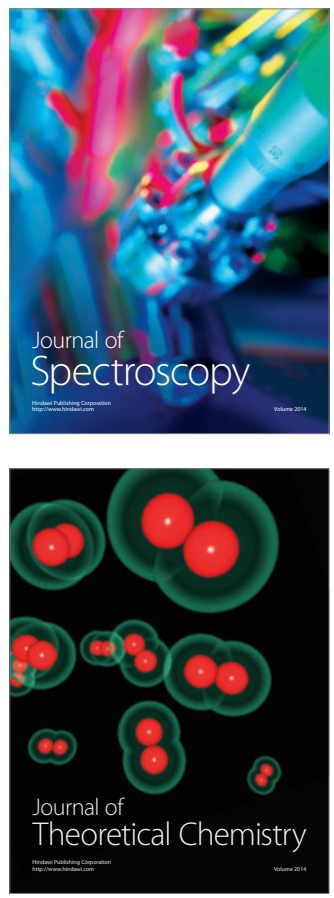
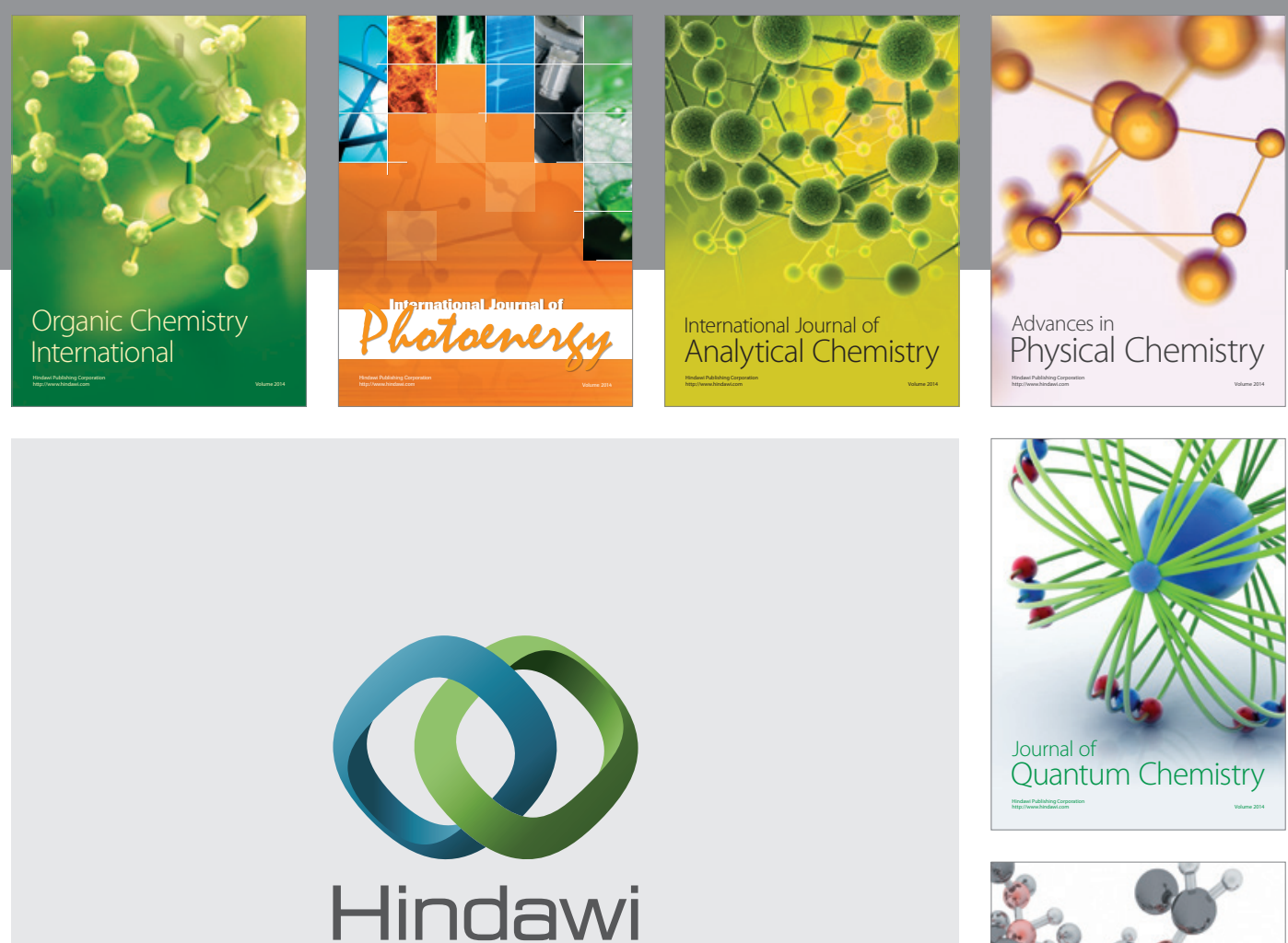

Submit your manuscripts at

http://www.hindawi.com

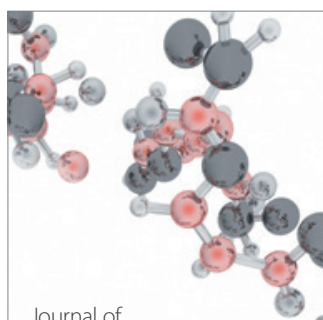

Analytical Methods

in Chemistry

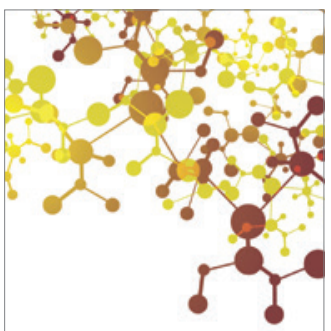

Journal of

Applied Chemistry

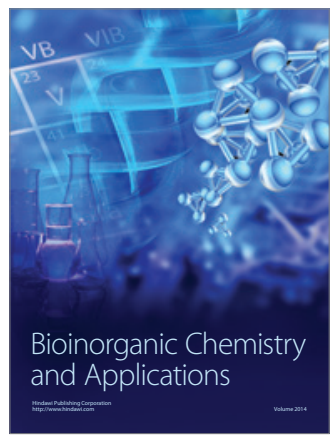

Inorganic Chemistry
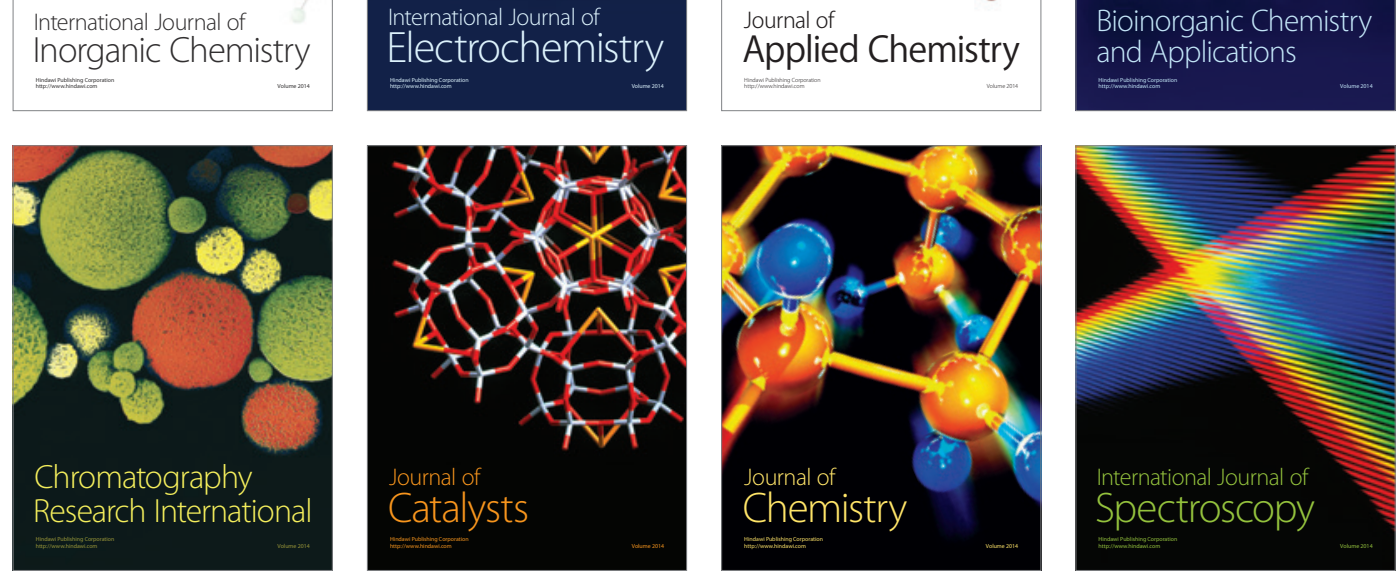